\title{
aniki
}

Revista Portuguesa da Imagem em Movimento

Portuguese Journal of the Moving Image

\section{O cinema existe e resiste. Longa duração, análise fílmica e espectatorialidade nos filmes de Lav Diaz Lúcia Ramos Monteiro ${ }^{1}$}

"S'il y a des marges, y a-t-il encore une philosophie, la philosophie?"

(Derrida 1972, IX)

\section{Introdução}

Nos últimos anos, textos críticos (Flanagan 2008; James 2010; Romney, 2010; Shaviro, 2010; Dargis, 2011, entre outros) e trabalhos acadêmicos (alguns exemplos: Balsom, 2007; Koepnick, 2014; de Luca e Jorge, 2016) vêm dando atenção ao que seria uma tendência do cinema contemporâneo: a emergência de filmes caracterizados pela "longa duração," por "planos longos" e por uma sensação difusa de "lentidão." A partir de qual duração um plano deve ser considerado longo? Numa tentativa de tornar a discussão mais objetiva, evoca-se, por vezes, a medição da duração média dos planos de certo filme (average shot lenght, ou ASL). Mas seria possível determinar que um filme é longo para além da impressão subjetiva de um espectador que se entedia, se distrai - ou cochila - durante a projeção?

Subsiste a dificuldade de definir longa duração sem evocar a sensação de lentidão - grande parte dos textos sobre o slow cinema de fato incluem a duração longa dos planos entre os pilares desse movimento, também de difícil conceituação. Para Balsom (2007), lentidão e duração estão associadas à escala monumental dos planos, como estratégias de "contestação do ritmo frenético de edição presente na mídia contemporânea" e de desafio da concepção que vê no cinema "um território do choque e da distração." Flanagan (2008) elenca algumas características da "estética da lentidão": planos longos ou extremamente longos, estrutura narrativa discreta e "ênfase na quietude do cotidiano." Na tentativa de sistematização da questão proposta por de Luca e Jorge, slow cinema é um "movimento cinematográfico desestruturado, feito de filmes e práticas díspares conceituadas enquanto grupo por seu estilo comparável” $(2016,4)$.

A longa duração não é exclusividade dos tempos atuais. A história do cinema no século $\mathrm{XX}$ é pontuada por diversos e

\footnotetext{
${ }^{1}$ Universidade de São Paulo, Escola de Comunicações e Artes, São Paulo, 05508020, Brasil. 
memoráveis filmes longos, nos mais variados registros - Gance, Wahrol, Rivette, Hoffman, Bertolucci, Bergman, Oliveira, Lanzmann, Wiseman, Sokurov e Tarr são apenas alguns dos mais reconhecidos autores que se aventuraram em longas-metragens com mais de três horas de duração -, e de filmes marcados por inesquecíveis planos-sequência - Ninotchka (Lubitsch, 1939), A Corda (Hitchcock, 1948), Gertrud (Dreyer, 1964), O ano passado em Marienbad (Alain Resnais), Soy Cuba (Mikhail Khalatozov, 1964), O Sacrifício (Tarkovsky, 1986), etc.

Qual seria a novidade trazida pelo cinema do século XXI para tal discussão? Certos autores veem o fenômeno como uma resposta à aceleração da edição nos filmes comerciais, nomeadamente os realizados em Hollywood (Balsom 2007; Flanagan 2008), o que, no limite, configuraria um gesto de resistência em tempos de capitalismo tardio, exigência redobrada de atenção, eficiência e disponibilidade (Crary 2012 e 2014). Para Jacques Aumont, se a partir do início dos anos 2000 tornaram-se numerosos os filmes que "cultivam a duração dos planos," trata-se menos de um desejo de "ralentar o ritmo" do que da tentativa de "levar ao limite uma certa lógica do plano, enfatizando seu valor de unidade autônoma e diminuindo sua função de elemento dentro de um conjunto" (Aumont 2015, 60-61). Não se pode olvidar que o digital traz a possibilidade técnica de registrar um plano por períodos muitos superiores aos permitidos pela filmagem em película - mas será isso suficiente para explicar, ainda que parcialmente, a recorrência da longa duração em obras recentes? ${ }^{2}$

Babette Mangolte (2003) dedica um ensaio perspicaz à relação entre filme digital e duração. Por um lado, ela defende que só a película é capaz de transmitir ao espectador a sensação de duração, sobretudo em razão da pulsação do obturador e da inscrição física da matéria-tempo sobre a superfície foto sensível; por outro lado, afirma que o digital convida a uma mudança de postura por parte de quem está atrás da câmera: deixa de se pensar em termos de "planos" e filma-se de maneira contínua, sem cortes, principalmente para manter a integridade do som. Além disso, os processos mentais envolvidos na edição não-linear complexificam a operação do corte. Assim, ainda que seu ponto de partida seja a constatação da incapacidade dos suportes eletrônicos de reproduzir a passagem do tempo traduzida na questão "Por que, para a imagem digital, é tão difícil transmitir a duração?" (Mangolte 2003, 263) -, Mangolte acaba concluindo que as câmeras digitais seriam menos propensas do que as analógicas a "serem desligadas" e, por isso, favoreceriam planos

\footnotetext{
${ }^{2}$ Vale observar que cineastas como Béla Tarr, Jia Zhang-ke, Lav Diaz e Tsai MingLiang elegem o plano-sequência e o plano longo como formas de predileção antes de filmarem em suporte digital - no caso de Tarr, há, inclusive, a manifesta recusa do digital.
} 
intermináveis, incitando mesmo à dissolução da própria ideia de plano:

A câmera digital (...) requer um tipo de concentração muito distinto por parte da pessoa que manuseia a câmera. Você fica muito mais envolvido com o seguir do que com o olhar. A gravação do som precisa ser mantida, e por isso você evita pensar em planos. Você se recusa a desligar a câmera e pensa em termos de sequências de longa duração, de tempo ininterrupto e som contínuo. (2003, 270)

Tendo filmado em $35 \mathrm{~mm}$ e em suporte digital, em geral ocupando ele próprio a posição de montador, o realizador filipino Lav Diaz (n. 1958) encarna em seu cinema mais recente as contradições que Mangolte descreve na relação do digital com a duração, valorizando o plano enquanto unidade plena de sentido, conforme coloca Aumont. O presente artigo debruça-se sobre a ambivalência da questão da longa duração na obra do cineasta, que convida a uma interrogação profunda sobre novas (e velhas) formas de espectatorialidade. Por um lado, a longa duração em Diaz pode ser apontada como recurso estilístico privilegiado para afirmar a marginalidade de um certo cinema, um certo cinema filipino, funcionando, em última instância, como alegoria de um tempo histórico dilatado, marcado pelos cataclismos da história nacional (a colonização espanhola, a ocupação estadunidense, a ocupação japonesa, a ditadura de Marcos). Por outro, a longa duração configura-se como um obstáculo não só para o acesso a seu cinema (o que reforçaria sua posição marginal), mas para a crítica e a análise fílmica, que se "distraem"3 com a duração ou lentidão ${ }^{4}$, deixando outras questões em segundo plano - as referências e citações cinefílicas; a forma literária dos diálogos; a relação com teatro, performance, pintura, literatura e outras artes; o tratamento da luz; a riqueza linguística; etc.

A duração extremada dos planos e dos filmes de Lav Diaz pode, de saída, ser encarada como reiteração de uma tripla (e eletiva) marginalidade: a econômica (posição marginal dentro das grades de programação do circuito comercial); a estética (em função de sua radicalidade e do difícil enquadramento em categorias e gêneros); e a geopolítica (marginalidade que seria comum a todo cinema terceiro-mundista, nem hollywoodiano, nem europeu ${ }^{5}$ ). A questão

\footnotetext{
${ }^{3}$ A dialética entre atenção e distração, abordada por Crary (2012), será retomada mais adiante.

${ }^{4}$ Ingawanij (2015) observa que o discurso sobre o "slow cinema" pode tornar-se improdutivo, sobretudo para a análise da cinematografia de Diaz, ao colocar a postura contemplativa como base da atribuição de valor artístico.

${ }^{5}$ É verdade que o cinema de Diaz circula em festivais internacionais e se beneficia de financiamentos europeus (notadamente o fundo Hubert Bals, ligado ao Festival de Roterdã), mas sua economia de produção não é propriamente europeia, estando distante dos principais modelos centro-europeus. É preciso nuançar, de todo modo, a marginalidade do cinema nacional filipino dentro da geopolítica do cinema. O cinema de um país situado na periferia do sistema capitalista mundial é
} 
da duração seria assim particularmente propícia a uma abertura da estética aos estudos culturais, antropológicos e pós-coloniais. Esse cruzamento implica no reconhecimento, defendido por DidiHuberman a partir de Warburg e Benjamin, da potência crítica de obras singulares, ou seja, no reconhecimento da dialética entre singularidade e totalidade, e da capacidade de uma obra singular interpelar e transformar toda a história da arte que lhe antecede (Didi-Huberman 2009).

No caso dos filmes de Diaz mais francamente históricos, a longa duração pode ser encarada como alegoria do tempo histórico filipino, marcado por catástrofes que não se curam, por permanências e repetições. Nesse sentido, os 643 minutos de Evolution of a Filipino Family (Ebolusyon ng isang pamilyang Pilipino, 1993-2004), filme em preto e branco realizado ao longo de dez anos, agregam dramaticidade à saga dos Gallardo, família rural pobre que enfrenta toda a sorte de dificuldades durante o período que cobre toda a ditadura de Ferdinando Marcos (1965-1986) e as turbulências da Revolução do Poder Popular, movimento de resistência que consegue provocar a queda do presidente. Mais recentemente, ao fazer, em 485 minutos, também em preto e branco, uma reconstituição histórica dos acontecimentos ligados à Independência das Filipinas, em 1898, mesclando-a à literatura de José Rizal (1861-1896), A Lullaby to the Sorrowful Mystery (Hele sa hiwagang hapis, 2016) dá visibilidade aos períodos de espera enfrentados pelos revolucionários e enfatiza a duração da busca de Gregoria de Jesus (Hazel Orencio), que nunca encontrou o corpo de seu marido, o líder revolucionário Andrés Bonifacio. Prenunciando uma história pontuada por desaparecidos, o tempo jamais findo do luto impossível de Gregoria ecoa outros filmes de Diaz, como Melancholia (2008). Numa leitura alegórica, a perda de memória sofrida pela personagem-título de Florentina Hubaldo, CTE (2012), vítima de repetidos abusos e violências, funcionaria à imagem da própria história filipina. Os 360 minutos da narrativa não conduzem a qualquer tipo de redenção: acentuam, pelo contrário, persistências e repetições.

O cineasta, no entanto, costuma aborrecer-se com a questão da longa duração e procura afastar-se do rótulo "slow cinema", dizendo que se trata tão somente de "cinema." Tal como o pensa-

forçosamente periférico. No entanto, conforme sublinham Shohat e Stam (2006), a história do cinema filipino abarca importantes surtos de produção, e cedo registram-se cinquenta, cem filmes por ano, fato observado já por Georges Sadoul. A premissa da ideia automática de marginalidade é a centralidade absoluta de Hollywood como "um tipo de langue em relação à qual todas as outras formas são variações dialéticas, de modo que o cinema de vanguarda se encontra reduzido a um carnaval de negações do cinema dominante" (Shohat e Stam 2006, 62). No que diz respeito ao cinema filipino dominante, Diaz recusa aceitar que seu cinema estaria à margem: "trabalho para destruir essa divisão, clássica, entre cinema indie e cinema industrial" (Diaz 2016).

6 "It's not slow cinema, it's cinema," afirmou Diaz em entrevista coletiva, por 
mento derridiano sobre a margem da filosofia, que acaba por interrogar o que é filosofia (Derrida, 1972), a conversa sobre duração conduz a um questionamento sobre a duração instituída das sessões comerciais e o tempo da arte. Nascido em 1958 na ilha de Mindanao, Lavrente Indico Diaz cresceu longe dos grandes centros urbanos e, aos finais de semana, ia à cidade com o pai, para sessões duplas ou triplas, num ritual que seus espectadores atualizam. O cineasta já disse que o tempo lhe parece um conceito "ocidental," do qual ele se sente distante:

Você tem o sol subindo pela manhã, o anoitecer... nós temos as tempestades, as muitas estações e os diferentes períodos do ano. $\mathrm{O}$ ocidental impõe a sua perspectiva sobre as áreas do mundo que coloniza, e assim as coisas mudam. E você tem estas diferentes partes do dia, você come três vezes por dia, todas essas coisas. Mas tempo é um conceito da totalidade da humanidade. Sua grande luta, porque estamos lutando contra o tempo, estamos lutando contra a morte. Isto é o que André Bazin disse: "morte é a vitória do tempo". O cinema pode lutar contra isso. Você pode registrar isso e a humanidade não vai morrer porque será gravada como cinema. (2014).

Do ponto de vista da análise fílmica, a longa duração constituise como um problema, ecoando a dificuldade evocada por Bellour (1979), que poderia ser resumida no seguinte paradoxo: para analisar um filme, é necessário interromper seu fluxo mas, sem movimento, não há cinema. Afinal, como restituir, pela descrição, pelo comentário crítico ou pela reprodução de fotogramas ou sequências, a experiência da duração? A discussão sobre o desconforto do analista diante da duração extrema constituirá o primeiro ponto do presente artigo. Abrir-se para o corpo a corpo com filmes cujo visionamento toma o dia todo implica em interrogar posturas espectatoriais, estados de atenção e distração. A atenção tem papel central entre as preocupações do século XIX, que vê nascer o cinema, e está intimamente ligada à produtividade do trabalhador, que no capitalismo tardio aparece como problemática - não por acaso, a "doença" do déficit de atenção é vista como uma das mazelas de nosso tempo (Crary 2012). O cinema de Lav Diaz perturba conven-

ocasião da exibição de A Lullaby to the Sorrowful Mystery no Festival de Berlim, em 2016 ( $c f$. "Berlin film festival: diretor defends eight-hour movie that features hourlong lunch break," The Guardian, 19 de fevereiro de 2016, disponível em https://www.theguardian.com/film/2016/feb/19/coming-to-a-cinema-eighthour-film-lunch-break-philippines, último acesso a 10 de janeiro de 2017). Em 2013, numa entrevista em São Paulo, ele dissera: "Meu cinema não é longo, ele é livre, não faz parte das convenções. O limite de duas horas, uma hora e meia é só uma imposição da indústria para ter o máximo de lucro. Por que tratam o cinema desse jeito?" (Diaz 2013). Em 2008, após a primeira exibição de Evolution of a Filipino Family em Paris, testemunhei o diálogo entre Diaz e um espectador, que lhe perguntara qual seria a razão de um filme tão longo. O cineasta retorquiu com outra questão, algo como "Onde está estabelecida qual é a duração máxima de uma forma artística?" 
ções de centralidade do olhar e convida a plateia a desenvolver uma atenção flutuante. Suas narrativas que resistem a se fechar estariam, assim, na contracorrente das demandas do espectador contemporâneo tal qual ele vem sendo descrito: apressado, pouco fiel à sala de cinema e disposto a fruir da imagem em movimento em múltiplas plataformas. Em uma época marcada pela hiperconectividade, em que mesmo o tempo do sono é disputado pelo dever de estar alerta e disponível (Crary 2014), não deixa de ser subversiva a proposta de permanecer numa sala escura durante centenas de minutos em estado de semi-vigília. E este será o último ponto abordado por nosso artigo. Se de fato a experiência da sala de cinema tornou-se uma entre várias possibilidades de fruição da imagem cinematográfica e os discursos sobre "o fim do cinema" ou o "pós-cinema" são correntes entre os teóricos (Aumont 2012; Bellour 2011; Gaudreault e Marion 2013), Lav Diaz pode ser encarado como autor de uma obra de resistência, que ao mesmo tempo traz dificuldades para a análise e a crítica, manifesta a necessidade da sala escura e experimenta modalidades espectatoriais alternativas.

\section{Um cinema que resiste à análise}

Filmes de longa duração deixam o pesquisador que se propõe a estudá-los em uma posição incômoda, diante de uma série de problemas práticos. Como encontrar tempo para ver, rever, localizar fotogramas, citar, comparar? Como traduzir, pela descrição textual acompanhada da reprodução de alguns fotogramas, a experiência da duração? Mesmo quando é possível incluir um trecho, os efeitos de repetição e acumulação que as imagens adquirem ao longo do visionamento completo esvaem-se, se não de todo, ao menos parcialmente. Tais dificuldades, inerentes à atividade de análise fílmica, foram abordadas por Bellour $(1979,2009)$ e, mais recentemente, por Mroz (2012), que chama a atenção para a tendência de teóricos do cinema de privilegiar momentos particulares extraídos do fluxo do filme em detrimento da continuidade temporal, espécie de força potencialmente ameaçadora, presente no subtexto dos artigos analíticos.

A dificuldade de acessar diretamente o tempo fílmico ganha contornos específicos no confronto com filmes de duração extremada e, no corpo a corpo com a obra de Lav Diaz, aparece de maneira especialmente pronunciada. Prova do obstáculo que a longa duração representa para close-viewings dos filmes de Diaz está nos textos críticos a seu respeito, que não raro contentam-se em constatar - por vezes jocosamente - que seus filmes são longos. ${ }^{7}$

\footnotetext{
${ }^{7}$ Um exemplo é o título "Director defends eight-hour movie that features hourlong lunch break" (The Guardian, 19 de fevereiro de 2016, art. cit.); outro está na seguinte passagem: “At least 'Lullaby's' verbiage occasionally, if inadvertently, proves self-chastising: In a film short on laughs, chuckles rippled through the
} 
Diaz é autor de 27 filmes com duração de quatro, seis, oito, dez horas, compostos de planos longos (que frequentemente superam os 10 minutos) e dificilmente enquadráveis em gêneros tradicionais. São pouco visíveis fora da sala escura e, mesmo no âmbito dos festivais que os programam e premiam, a dificuldade de certo modo subsiste, já que são em geral exibidos de maneira contínua, vez ou outra com intervalos curtos a cada duas ou três horas, suficientes para adquirir novas entradas e não muito mais. Nos casos em que o "fetiche" 8 de possuí-los é satisfeito, de quanto tempo precisaria de dispor o analista para conseguir "conhecer seus filmes tão bem quanto o próprio cineasta," homenagem "natural" para alguém que escreve sobre um realizador que admira, como colocava Truffaut (1954)? No lugar de poder "citá-los" com precisão, seus estudiosos devem, em alguma medida, trabalhar com "blocos de memória incertos" (Bellour 2011, 40).

Quando interrompe o fluxo do filme para isolar alguns fotogramas, o analista de cinema elimina o movimento em favor de um "arrêt sur image," de modo que seu objeto desaparece. A obra cinematográfica, diz Bellour,

é propriamente incitável, pois o texto escrito não é capaz de restituir o que apenas o aparelho de projeção pode trazer: um movimento, cuja ilusão garante a realidade. É por isso que as reproduções, mesmo de fotogramas, apenas manifestam um tipo de impotência radical em assumir a textualidade do filme. (...) $\mathrm{O}$ congelamento da imagem, e o fotograma que ele reproduz, são simulacros; eles não cessam de fazer com que o filme escape, mas permitem paradoxalmente que fuja enquanto texto. $(1979,40)$

A dificuldade de acesso ao filme era uma realidade cotidiana para a maioria dos críticos e pesquisadores à época em que Bellour escrevia as linhas acima, o que implicava em uma escrita baseada sobretudo na memória do visionamento em sala. Três décadas mais tarde, o autor retorna à questão num momento em que a fruição do cinema se dá nas mais diversas plataformas e que o espectador (ou estudioso) em geral pode sem maiores dificuldades possuir os filmes que lhe interessam.

No que se refere ao trabalho de análise posto em prática pelo presente artigo, a opção foi reproduzir fotogramas, ainda que por vezes a imagem fixa subtraída de um plano contradiga a sensação que dele se tem na duração. Comecemos pelo plano de abertura de Florentina Hubaldo, CTE (2012). Hazel Orencio, presença constante

Berlin audience 20 minutes from the close, following one character's solemn promise of relief: 'In a little while, the pain shall end'" (Lodge 2016).

${ }^{8}$ Em estreito diálogo com o "espectador pensativo" descrito por Bellour (1997), Laura Mulvey (2007) aprofunda sua análise sobre o fetichismo característico do espectador contemporâneo, possessivo. A "citação" de um filme - de uma sequência, plano ou fotograma - é um tema discutido por Bellour em "Le texte introuvable" (Bellour 1979) e retomado em artigos posteriores (Bellour 2009). 
na filmografia de Diaz, interpreta a personagem-título, mulher que sofre diversos tipos de abuso ao longo do filme e que, apesar das inúmeras tentativas de fuga, sempre acaba aprisionada novamente. De volta à casa paterna, é vítima de novas violências. Para Nadin Mai (2015), trata-se de uma alegoria da história das Filipinas, país submetido a toda a sorte de abusos e invasões.
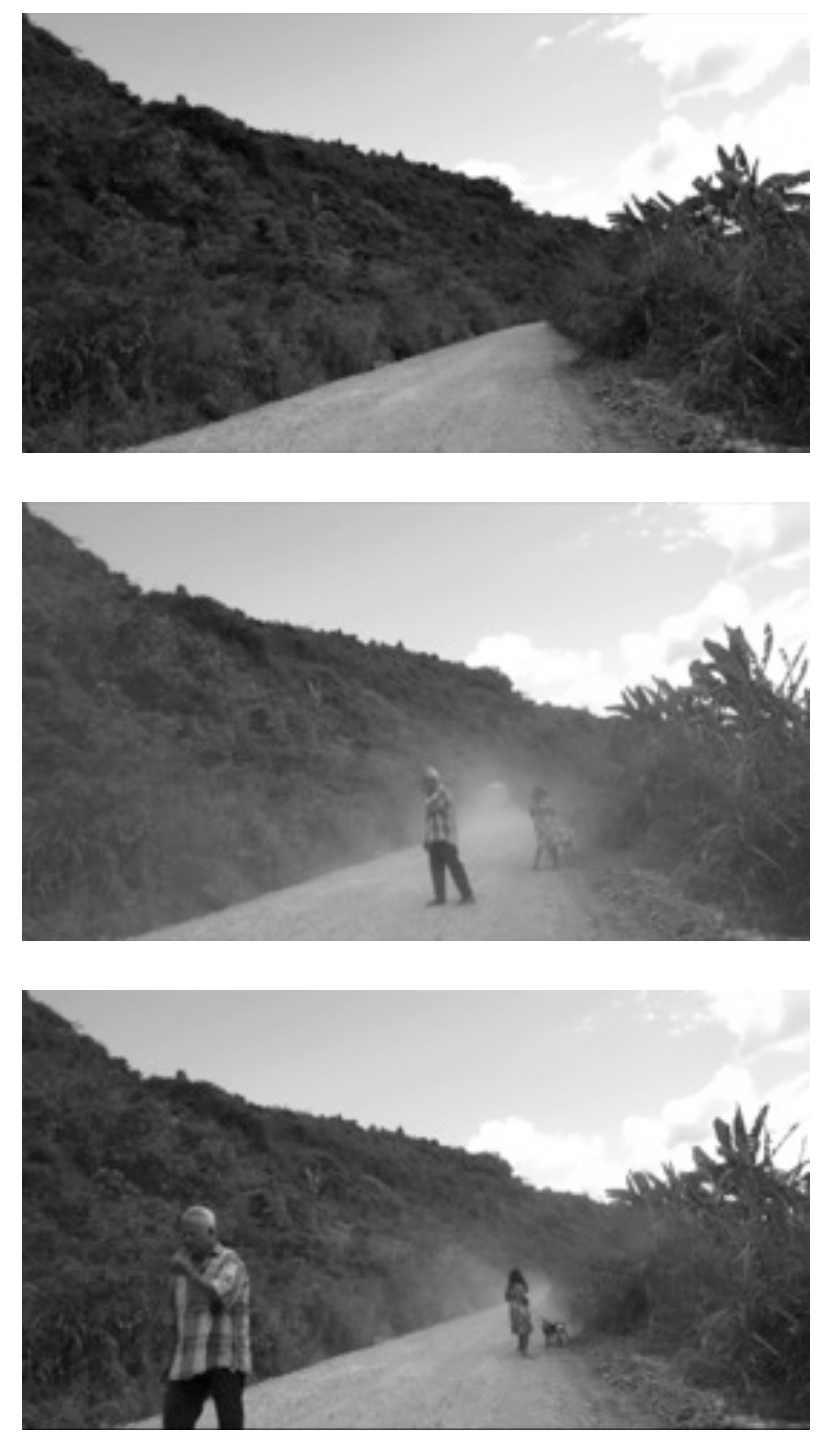

Imagem 1 : Três fotogramas do plano de abertura de Florentina Hubaldo, CTE (Lav Diaz, 2012), com duração de 5' | (c) Lav Diaz

Florentina Hubaldo se abre com um plano de uma estrada que corta a floresta. Vistos congelados, os três momentos desse plano inicial reproduzidos acima parecem organizados de maneira convencional: há um ponto de fuga no fundo do quadro, de onde a ação surge; a ação ocupa a frente e o centro do quadro, ladeada por porções escuras que lhe serviriam de margem, ornamento. Construído, portanto, em pleno acordo com as convenções da perspectiva, o quadro pode ser dividido em três porções verticais desiguais: a es- 
trada no centro e, de um e outro lados, porções da floresta, escuras, maior à esquerda, menor à direita. Na parte inferior do quadro, a estrada ocupa maior espaço, enquanto na parte superior, ela praticamente desaparece, de modo que uma pessoa que percorra a estrada aproxima-se da câmera conforme avança.

A experiência do filme, no entanto, não confirma tal descrição. Passam-se longos minutos antes que qualquer movimento seja notado na estrada e, enquanto nada ocorre no centro, o filme convida o espectador a nutrir pelas imagens um olhar centrífugo, em direção à periferia do quadro, indo na contramão das convenções renascentistas com relação à perspectiva e à centralidade. Ele observa, na margem direita, folhas do coqueiro balançarem e, no alto, o desenho da nuvem que se desfaz e se refaz. Tal tipo de percepção reedita o espanto dos primeiros espectadores de Repas de Bébé (1895), dos Lumière: as folhagens em movimento no fundo da imagem - o fundo cinematográfico - causavam mais frisson do que a performance do protagonista, um bebê a comer (Bonamy 2013). À ideia segundo a qual o décor seria um lugar de neutralidade em benefício da lógica ficcional, à ideia de uma passividade do fundo contrastada com a ação da figura, Bonamy, em Le fond cinématographique, opõe um olhar que devolve ao fundo cinematográfico sua importância, lembrando que, quando de seu surgimento, foi também porque o movimento envolvia o fundo que o cinema se demarcou do teatro, em que os fundos pintados eram, de fato, majoritariamente imóveis.

É só depois de um certo tempo que notamos, no "pano de fundo," algo que avança em nossa direção. Uma mulher? Um homem? Animais? O tempo trará a resposta. Esse mesmo sistema se repetirá depois de uma hora de filme, com algumas diferenças. A estrada do início será substituída por um curso de água. Nesse segundo plano, de 10 minutos de duração, algo também avança em nossa direção. Depois de alguma espera, identificamos um homem, mas ainda é difícil dizer se ele anda à direita do curso de água, à esquerda ou, talvez - e é o caso - se caminha com os pés dentro de água. É a imagem do homem que habita a "terceira margem do rio," para retomar o título do conto de Guimarães Rosa, adaptado ao cinema por Nelson Pereira dos Santos (1994).

Se Lav Diaz insiste em convidar seu espectador a observar as margens da imagem, as configurações aqui reproduzidas reiteram sua materialidade, como a ecoar estranhamente os dizeres com que André Bazin encerra seu "Por um cinema impuro. Defesa da adaptação.” Escrito em 1951, o texto-manifesto do crítico francês advogava contra uma postura essencialista do cinema, afirmando sua necessidade de inspirar-se e abrir-se à influência de outras artes - a literatura e o teatro principalmente, pela complexidade que agregam à estrutura narrativa do filme -, numa época em que o espetáculo do cinema "puro" já não bastava. 

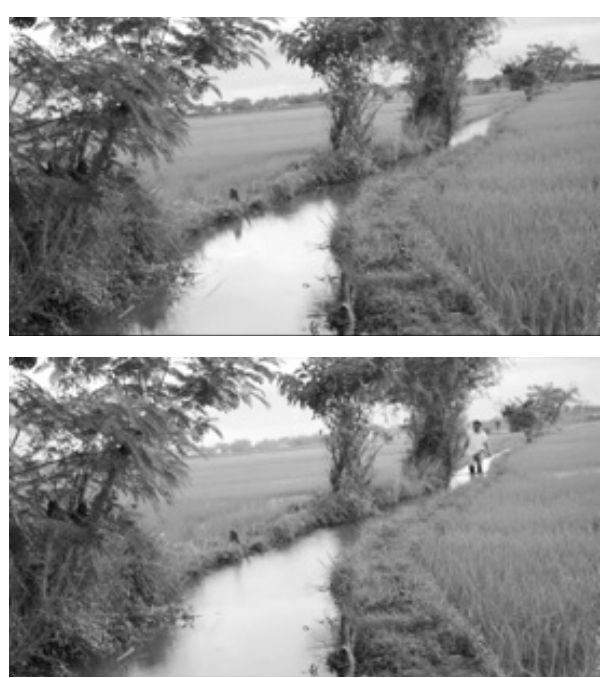

Imagem 2 : Quatro fotogramas de Florentina Hubaldo, CTE (Lav Diaz, 2012). Plano inicial da segunda parte, com 10’ de duração. | (c) Lav Diaz

Bazin lança mão de suas costumeiras metáforas geográficas para fazer uma verdadeira apologia das margens, daquilo que o cinema ganharia ao admitir-se poroso, aberto a contaminações:

Já não basta inventar a montagem rápida ou mudar o estilo fotográfico para emocionar. O cinema entrou insensivelmente na época do roteiro; vale dizer, de uma inversão da relação entre o fundo e a forma. (...) Como os rios que escavam definitivamente seu leito e só têm força para levar suas águas para o mar sem arrancar um grão de areia de suas margens, o cinema se aproxima de seu perfil de equilíbrio. Já se foram os tempos em que bastava fazer "cinema" para ter os méritos da sétima arte. Esperando que a cor ou o relevo deem provisoriamente a primeira forma e criem um novo ciclo de erosão estética, o cinema não pode conquistar mais nada na superfície. Só lhe resta irrigar suas margens, insinuar-se entre as artes nas quais ele cavou tão rapidamente suas gargantas, investi-las insidiosamente, infiltrar-se no subsolo para abrir galerias invisíveis. (2010, 103-104)

À defesa baziniana da porosidade do cinema em relação às outras artes em sua feitura e em sua fatura, discutida daqui em diante, sobretudo à luz de A Lullaby to the Sorrowful Mystery, somam-se a impureza também enquanto objeto dos estudos culturais e, ainda, a discussão do contato do cinema com outras expressões artísticas no que diz respeito a sua fruição, e em especial com as formas de espectatorialidade da imagem em movimento que não dependem da sala de cinema. 


\section{Olhar para a margem e distração subversiva}

Cansado de esperar que algum evento venha ocupar o centro da imagem, o espectador de Florentina Hubaldo, CTE exercita, já desde o plano inicial, o deslocamento de seu olhar em direção às margens da imagem, lugar normalmente ocupado apenas pelo ornamento (Derrida 1972), pelo que está no limiar entre imagem e não-imagem, entre campo e fora de campo. Em Florentina Hubaldo, CTE por vezes ocorre que as margens da imagem são de fato imagens de margens a floresta que margeia a estrada, a plantação que margeia o curso de água. Esses e outros espaços intersticiais, em geral obscuros, ganham visibilidade no cinema de Diaz, que parece encará-los em sua grande potência polissêmica e metafórica.

Homi K. Bhabha, que vê a virada do século XX para o século XXI como um período marcado pelo abandono das singularidades de classe e de gênero enquanto categorias conceituais e organizacionais primárias, defende os novos espaços "intersticiais" como lugares privilegiados para a negociação das experiências intersubjetivas e coletivas de pertencimento, nomeadamente à nação (Bhabha 1998, 19-20).

De acordo com Kristeva, as margens da nação são constantemente confrontadas a uma dupla temporalidade: o processo de identidade constituído pela sedimentação histórica (o pedagógico) e a perda de identidade no processo significativo de identificação cultural (o performativo). O tempo e o espaço na construção da finitude da nação em Kristeva são análogos a meu argumento segundo o qual a figura do povo emerge na ambivalência narrativa de tempos e sentidos disjuntivos. A circulação simultânea do tempo linear, cursivo e monumental no mesmo espaço cultural constitui uma nova temporalidade histórica que Kristeva identifica com estratégias feministas de identificação política de base psicanalítica. (1998, 216; tradução ligeiramente modificada ${ }^{9}$ )

Lav Diaz interessa-se pela história nacional filipina - recorrente no cinema filipino, o tropo da independência, base das chamadas ficções fundacionais (Sommer 2004), recebe atenção especial do cineasta. Episódios da história nacional são narrados e alegorizados, num clamor para que tragédias não se repitam, e no afã de "conscientizar," não sem reconhecer a frustração diante da pouca

\footnotetext{
${ }^{9}$ No original: "The border of the nation Kristeva claims, are constantly faced with a double temporality: the process of identity constituted by historical sedimentation (the pedagogical); and the loss of identity in the signifying process of cultural identification (the performative). The time and space of Kristeva's construction of the nation's finitude is analogous to my argument that the figure of the people emerges in the narrative ambivalence of disjunctive times and meanings. The concurrent circulation of linear, cursive and monumental time, in the same cultural space, constitutes a new historical temporality that Kristeva identifies with psychoanalytical informed, feminist strategies of political identification" (Bhabha 1994, 219-220).
} 
visibilidade. ${ }^{10}$ Se tal postura, manifesta em algumas entrevistas (Diaz 2016), lembra o discurso de cineastas do chamado Terceiro Cinema, o cineasta se distancia desse movimento e das narrativas fundacionais ao chamar atenção para o fenômeno de dissolução que envolve a identidade nacional, a ideia de cinema nacional e as próprias bases definidoras do medium cinematográfico (Monteiro 2016). Não há como pensar as identidades, hoje, depois do aporte dos estudos culturais, sem levar em conta os hibridismos e as dinâmicas, do mesmo modo que depois da revisão dos conceitos de "nação" e "nacionalismo" pela historiografia - Hobsbawn (1990; 2012), Anderson (2008) -, é preciso interrogar a própria categoria de cinema nacional.

A reivindicação do espaço da margem não parece equivaler, no entanto, à adoção de uma postura marginal, como um outro em relação ao cinema filipino mais popular e comercial ou, como vimos acima, em relação ao cinema mais "eficiente" e acelerado. Para a realização de A Lullaby to the Sorrowful Mystery, Diaz convoca atores filipinos conhecidos, presentes nas grandes produções do país, enfatizando que não se trata de negar um cinema para afirmar a existência de outro (Diaz 2016). A Lullaby... é, afinal, uma forma peculiar, transgressiva, de "narrativa fundacional" (Sommer 2004).

Estão presentes no filme algumas das bases da identidade e do nacionalismo filipino, como a literatura de Rizal e o cancioneiro tradicional popular, evocado já no título. Mas, se nas ficções fundacionais estudadas por Sommer o entrelaçamento entre o privado e o público se dá em nome de uma estrutura teleológica de redenção e promessa de prosperidade, no filme de Diaz a aliança entre destino individual e destino coletivo se dá na chave da desesperança, da dissolução. A alegoria do destino da nação proposta por Diaz aproxima-se do que defende Jameson (1986): no lugar da teleologia de esperança e redenção, lamento diante do destino de um povo que não cessa de dissolver-se - colonização, mestiçagem, exílio, abusos são apenas algumas das modalidades que essa dissolução toma na tela, inclusive em seu sentido físico-químico, ou seja, enquanto diluição da nitidez da imagem diante de uma grande presença da água.

A dissolução enquanto fenômeno cultural encontra ressonância na experiência de cinema proposta por Diaz, de estiramento no tempo e de contaminação da imagem cinematográfica por outras práticas artísticas e de espetáculo. A literatura, ${ }^{11}$ o teatro e o espetá-

\footnotetext{
${ }^{10}$ Numa entrevista recente, o realizador fala da imensa tristeza diante da pouca visibilidade de A Lullaby... em seu lançamento e conta sua intenção de organizar sessões públicas em distintas localidades do país para que o filme possa ser de fato visto, trata-se de "reeducar as massas" (Diaz 2016).

${ }^{11}$ Referências literárias pontuam toda a obra de Diaz. Alguns exemplos: The Day Before the End, curta-metragem realizado por Diaz em 2016 e premiado no Festival de Oberhausen, é uma adaptação de A Tempestade, de Shakespeare (1610-1611);
} 
culo forense são fundamentais para A Lullaby to the Sorrowful Mystery, filme ambientado no final do século XIX, momento em que o cinema chega às Filipinas, encarnando de maneira peculiar a "impureza" defendida por Bazin. Diaz confessa-se um admirador do crítico francês (Diaz 2014; 2016), e, se à primeira vista isso pode ser identificado em seu gosto por planos longos (elogiados em "Montagem proibida") ou em seu realismo (cujos preceitos estão em "Ontologia da imagem fotográfica"), a análise de $A$ Lullaby... ganha no contato com o pensamento baziniano presente em "Por um cinema impuro. Defesa da adaptação," de 1951. Para Bazin, se o cinema deve estar atento ao exemplo das artes "mais velhas," isso não significa "submeter-se" a elas ou "diminuir-se," mas ocupar espaços marginais, limítrofes, investir no contato com outras formas artísticas.

Lúcia Nagib e Anne Jerslev (2013) investem a ambiguidade das conotações atuais de tal expressão, entendendo "impureza" não apenas como abertura do cinema a outras artes, mas referindo-se também aos cinemas "interculturais" enquanto espaços instáveis de sincretismo e creolização. No caso de A Lullaby to the Sorrowful Mystery, as "impurezas” são abundantes, nessas duas acepções. Além de se constituir como uma adaptação da obra literária de Rizal, o filme contém números musicais e teatrais. Para mais, a multiplicidade de línguas faladas - tagalog, espanhol, inglês, latim, francês - dá materialidade para a "impureza" constitutiva da fundação nacional filipina. $^{12}$

O filme começa com um plano de escrita ${ }^{13}$ : alguém escreve uma carta, numa configuração que lembra Prologue to the great desaparecido (Prologo sa ang dakilang desaparecido, 2013), que abre caminho para A Lullaby... Qual uma floresta de caminhos que se bifurcam, o filme se organiza em uma narrativa dupla, talvez tripla. Há, em primeiro lugar, um filme histórico, pontuado acontecimentos

Evolution of a Filipino Family deve sua estrutura ao chamado "roman-fleuve" e às sagas familiares. Com efeito, a literatura oferece a Diaz não apenas objetos propícios à adaptação, mas um método. Ele afirma pensar na escrita de um romance ao criar a estrutura de seus filmes, e inspirar-se da poesia para neles introduzir sua visão de mundo (Diaz 2014).

${ }^{12}$ Anderson (2005), que dedicou boa parte de sua vida ao estudo do imaginário anticolonial filipino, sublinha a intensidade e a versatilidade linguística dos principais atores da independência do país, que mantinham correspondência com anarquistas em Cuba, na Espanha, na Áustria, no Japão. Rizal escrevia em espanhol, a língua do conquistador, tomando o cuidado de pervertê-la com expressões em tagalog. A Lullaby... restitui tal atmosfera internacionalista e sofisticada.

${ }^{13} \mathrm{O}$ gesto manual da escrita, do mergulho da pena no tinteiro ao desenho das letras no papel, é reforçado em inúmeros planos do filme. Anderson (2005) sublinha a temporalidade da comunicação ao final do século XIX: além das cartas escritas com caneta tinteiro, numa correspondência que cruzava oceanos com velocidade considerável, e que resistem hoje em arquivos, o telégrafo foi usado na articulação da independência filipina. 
reais ocorridos durante a Revolução Filipina (1896-1898). Em segundo lugar, está a adaptação da obra ficcional de José Rizal, autor dos romances Noli me tangere (1886) e El Filibusterismo (1891). Expoente das lutas pela independência filipina, o escritor aparece no começo do filme como personagem da história real, quando assistimos a sua execução, fora do quadro. Os versos do poema Mi ultimo adiós (1896) serão recitados depois e seu estilo ecoará em cada diálogo. A essa dupla narrativa, entre o histórico e o ficcional, acresce uma terceira camada, que poderíamos considerar "sobrenatural": a narrativa abarca aparições fantasmagóricas, entre o culto religioso, o mito e o sonho.

O filme que resulta da somatória desses três níveis narrativos é povoado por uma dezena de protagonistas e centenas de figurantes. Ações se desenvolvem em paralelo, num ritmo narrativo que, se não é frenético, tampouco percebe-se como monótono. Por quase duas horas, a procura pelo corpo desaparecido de Bonifacio em meio a uma vegetação densa, capitaneada por sua mulher, é encenada de modo admirável: Gregoria de Jesus busca vestígios do marido no solo, sob as folhagens, investigando pedaços de tecidos caídos entre os arbustos, numa expedição beckettiana, que volta sempre a seu ponto de partida. "Vocês ouviram tiros? De onde vinham?", pergunta ela com insistência. Mas a floresta fica entre duas montanhas e o eco impede a localização da fonte sonora.

A presença da música e, em particular, a "canção de ninar" sugerida no título contribuem para a modalidade de atenção que Diaz instaura, quase meditativa. A "canção" ouvida, "Jocelynang Baliwag," pertence a um gênero tradicional filipino que lembra a valsa, o "kundiman," e costumava ser executada à noite, em serenatas, cantada em tagalog com acompanhamento de violão ou violino. Com letras que podem tanto ser românticas quanto patrióticas, funcionando para ninar e para velar, o kundiman é em si um gênero impuro. Rizal chegou a compor uma canção do gênero, dotando-a de versos patrióticos, escritos em tagalog - Noli me tangere faz referência a ela. ${ }^{14}$ Popular ao final do século XIX, época em que a ação se situa, "Jocelynang Baliwag" é repleta de sentimentos revolucionários patrióticos e, por isso, ficou conhecida como "a Kundiman da Revolução.” A melancólica melodia é também de pesar, impregnada por um sentimento patriótico demasiadas vezes frustrado.

\section{Comunidade espectatorial, comunidade de memória}

Enquanto o capitalismo tardio avança pelas horas de sono, doravante transformadas em horas de trabalho, condenando-nos a um estado de atenção permanente (Crary 2014), é subversiva a proposta de

\footnotetext{
${ }^{14}$ Em espanhol, "aun que no sea." Cf. R. C. Bañas, "The music and theatre of the filipino people. Early music of the Filipinos", El Filipino, mars 1926, 16.
} 
Diaz: um filme de oito horas que embala seu espectador ao som de uma canção de ninar, contribui para um estado de atenção entre o sono e a vigília. Diaz abandona o direcionamento da atenção do espectador, de que o cinema seria mais capaz do que qualquer outra arte, de acordo com o estudo fundador de Hugo Münsterberg, escrito em 1916 (1983). Numa comparação com o teatro, o autor identifica a superioridade do cinema em conduzir o olhar do espectador através do encadeamento de planos de distintos valores, e isso apesar de que "falta, é claro, a palavra falada" (Münsterberg 1983, p. 30):

Se os movimentos das mãos de um ator no palco captam o nosso interesse, não olhamos mais a totalidade da cena. Vemos apenas os dedos do herói colados ao revólver com o qual vai cometer o crime. A atenção fixa-se integralmente na expressão arrebatada da mão (...). É como se todo o resto houvesse desaparecido e nesta mão se concentrasse, na precipitação dos acontecimentos, a totalidade da cena. Mas isto, no palco, é impossível: lá, nada pode sumir de verdade. A mão continua a ser apenas uma décima milésima parte do espaço total do palco; apesar de toda a sua dramaticidade, ela continua a ser um pequeno detalhe. $(1983,33)$

No cinema, o "ato de atenção" é capaz de "remodelar" o ambiente, nomeadamente em razão da existência do close-up:

a mão nervosa que agarra febrilmente a arma mortífera pode súbita e momentaneamente crescer e ocupar toda a tela, enquanto tudo o mais literalmente some na escuridão. (...) O close-up transpôs para o mundo da percepção o ato mental de atenção e com isso deu à arte um meio infinitamente mais poderoso do que qualquer palco dramático. (id., 34)

A decupagem didática é evidentemente ausente na montagem de A Lullaby.... Bellour, que faz referência ao estudo de Münsterberg para pensar nas transformações na postura espectatorial, afirma a existência de "dois cinemas" nos tempos atuais: de um lado, “o comercial global, dominante e dominado por todos seus produtos derivados," "fundado sobre uma estética degradada do choque estereotipado e uma violência indeterminada das imagens"; de outro, "um cinema cada vez mais local, diversificado, tornado mais internacional, que continua a buscar a atenção dos espectadores" (Bellour 2011, 34). Não é difícil enquadrar o cinema de Diaz nessa segunda categoria e ver seu espectador como "membro de uma comunidade restrita, mas de agora em diante estendida a dimensões planetárias" (Bellour 2011, 34).

A oposição entre atenção e distração não basta para entender as dinâmicas envolvidas na experiência de um filme como A Lullaby to the Sorrowful Mystery: ao invés de conduzir didaticamente seus espectadores, Diaz os convida a modularem voluntariamente atenção e distração. Essa abertura está em sintonia com o modo de espectatorialidade das imagens em movimento instaurado por sua 
forma instalatória, pautada pela possibilidade de entrar e sair em momentos aleatórios, ainda que a narrativa tenha começo, meio e fim, no que de certo modo atualiza a experiência dos surrealistas que entravam e saíam arbitrariamente de sessões de cinema parisienses.

Ao retornar, depois de um intervalo de três décadas, ao paradoxo da análise fílmica descrito em "O texto inencontrável," Bellour formula a hipótese de que, se ele pode ser atualizado hoje, é menos no cinema do que nas instalações que incorporam a imagem cinematográfica (em geral por meio do vídeo):

É historicamente no momento em que o filme se torna um texto cada vez menos inencontrável, sob o risco do que se perde em comparação com a sessão de cinema, que instalações constituídas de projeções parecem ocupar de certo modo esse lugar. (2009)

À diferença de outros cineastas identificados com o "slow cinema," como Abbas Kiarostami e Apichatpong Weerasethakul, os filmes de Lav Diaz vêm sendo exibidos na sala de cinema em detrimento do espaço de exposição e do circuito da arte contemporânea. Nos festivais que exibem seus filmes (Roterdã, São Paulo, Veneza, Berlim), eles são projetados nas salas, em sessões contínuas ou com pausas, com venda de ingressos tradicional. Fato raro na trajetória do cineasta, The Woman Who Left (Ang babaeng humayo, 2016), premiado em Locarno, de 226 minutos, tem sido distribuído comercialmente, em sessões contínuas. É verdade que têm sido realizadas retrospectivas suas em espaços da arte, como o Jeu de Paume, na França, e a London Gallery West, na Inglaterra. ${ }^{15}$ Ao menos por enquanto, quando seus filmes são vistos nesses ambientes, mantêm-se a obscuridade e o horário determinado das sessões, como no cinema - não há exibição em loop nem na relativa claridade do espaço expositivo, como sói acontecer com instalações de cineastas como Kiarostami, Weerasethakul, Tsai, Farocki, Varda, etc.

Estaria o cinema de Diaz em sintonia com o que sugere de Luca, ao apontar o "slow cinema" como ato de resistência ao estado de coisas atual do cinema, à fruição esfacelada das imagens em movimento em múltiplas plataformas? Haveria, na opção pela duração estendida, a escolha de uma modalidade de enunciação "que necessita da sala de cinema para que o contrato espectatorial seja inteiramente cumprido"? (De Luca 2016, 23). Como diz o autor, a imobilidade, o silêncio, a opacidade da narrativa e a própria duração fazem com que "o cinema da lentidão seja impróprio para visionamento doméstico e para os modos de interação espectatorial fragmentados e distraídos favorecidos pelas telas miniaturizadas" (De Luca 2016, 24).

\footnotetext{
${ }^{15}$ No Jeu de Paume, os filmes de Diaz eram exibidos no auditório, equipado como uma sala de cinema; na London Gallery West, um cinema foi criado dentro do espaço expositivo, com cadeiras e almofadas, mantendo-se a porta semi-aberta, de modo que o espaço do filme não era estanque à entrada de luz, de som e de espectadores durante a projeção.
} 
Talvez não haja um modo espectatorial ideal para fazer a experiência dos filmes de Lav Diaz: é possível tanto contemplar a beleza de planos escolhidos ao acaso quanto envolver-se em suas narrativas complexamente construídas, numa precisa gestão do suspense; é possível tanto ver os filmes no computador, numa lógica serial experimentada pela retrospectiva organizada na plataforma on-line Mubi, quanto mergulhar na sala escura horas a fio. Diaz afirma que não se preocupa com o conforto do público quando filma, pensa apenas na arte (Diaz 2013). De todo modo, é difícil ser espectador dele sem tomar consciência das condições de projeção, algo frequente no slow cinema (De Luca 2016, 25). A opacidade de seu cinema propicia uma postura espectatorial "consciente," corporal e mentalmente engajada na experiência da exibição.

Quando vistos em sala, filmes como Batang West Side, Evolution of a Filipino Family, Melancholia, Florentina Hubaldo, CTE e A Lullaby... acabam por favorecer a construção de uma comunidade de memória, numa atualização do pensamento de Benedict Anderson. Fica patente, nas sessões de cinema de Lav Diaz como nas páginas de José Rizal, que o historiador usa de exemplo, a sensação de um aqui e agora compartilhado e de acontecimentos testemunhado coletivamente: "a ficção se infiltra contínua e silenciosa na realidade, criando aquela admirável confiança da comunidade no anonimato que constitui a marca registrada das nações modernas" (Anderson 2008, 69). É preciso que uma comunidade testemunhe coletivamente os pontos-cegos do discurso historiográfico iluminados por Diaz.

A cada vez que uma fala ou uma imagem faz menção a algo que havia sido exibido anteriormente, minutos ou horas atrás, o espectador deve recorrer à própria memória. Ao final da sessão, fica o sentimento de uma experiência vivida de maneira compartilhada, de construção de uma memória comum, exercício necessário em se tratando de uma história tão sujeita a apagamentos e esquecimentos como a filipina.

\section{Conclusão}

Procuramos pensar a obra do cineasta filipino Lav Diaz com base na questão da longa duração, apontada como tendência do cinema independente contemporâneo, relacionada ao uso dos suportes digitais de gravação e exibição. A partir do estudo de Florentina Hubaldo, CTE (2012) e A Lullaby to the Sorrowful Mystery (2016), tentamos enfrentar algumas das dificuldades que a longa duração representa para a análise fílmica. Quando se interrompe o fluxo do filme para analisá-lo, citações e reproduções de imagens acabam por contradizer a experiência das imagens em movimento que o espectador e o analista só podem fazer na duração, numa reedição do paradoxo descrito por Bellour (1979). 
É frequente relacionar o apreço de Diaz por Bazin, a quem considera "maior do que qualquer cineasta" (2014), a sua propensão para o realismo e a realidade ontológica da imagem em movimento. Sem negar tais potencialidades, aqui o aporte baziniano é visto em seu elogio à impureza do cinema, presente em um texto em defesa da adaptação cinematográfica de obras literárias, indo na contramão da visão essencialista do cinema, que procurava distinguir, distanciar a "sétima arte" das demais formas de expressão artística.

Sobretudo, a questão do plano longo foi abordada do ponto de vista da postura espectatorial, interrogando-se a modalidade de atenção incitada pelo cinema de Diaz, subversiva no capitalismo tardio, quando se exige uma disponibilidade e um estado de alerta permanentes (Crary 2014). Se a modernidade investe na atenção e dela depende, tendo na atenção do espectador de cinema um de seus feitos, como enxergar a postura meditativa e quase adormecedora que Lav Diaz instaura em seus espectadores quando os embala durante oito horas (teoricamente o tempo de sono necessário a um adulto), como em A Lullaby to the Sorrowful Mystery, ao som de uma canção de ninar e de pesar? Pensando sobre os aportes do cinema identificados por Münsterberg (1983) no direcionamento da atenção do espectador, e levando em conta também a lógica do choque usada pelo cinema mais comercial, pode-se afirmar que Diaz abstém-se de conduzir didaticamente a atenção de seu público, e convida-o a exercitar modalidades de percepção diversas e variáveis.

A questão, no fundo, é também como pensar os limites da duração de um filme ou um plano, como conceituar a duraçãolimite? Como enfrentar tal interrogação que, sem deixar de ser fundamental, obstrui a análise mais em detalhe da obra de Diaz? A questão da longa duração no cinema de Diaz foi abordada primeiro do ponto de vista epistemológico, enquanto problema para a análise fílmica. Os planos longos foram encarados, aqui, menos dentro da perspectiva ontológica de sua propensão ao realismo ou à verdade e mais do ponto de vista da experiência do espectador, da modulação de sua atenção. Se a relação entre duração extremada e tecnologia digital nos parece incontornável, o cinema de Diaz reitera uma postura cinefílica que depende da sala de cinema e das comunidades que nela se criam. Tal postura tende, hoje em dia, a tornar-se marginal, em meio à profusão de plataformas individuais para a fruição da imagem em movimento com as quais a sala escura concorreria.

Porque é difícil pensar nas margens sem colocar em questão "a coisa," seria necessário, a exemplo de Derrida, em primeiro lugar nuançar a centralidade de um suposto cinema dominante, tanto no que diz respeito à produção, quanto com relação à estética. Uma vez que trabalhar o conceito de limite implica em trabalhar "no limite do conceito," é impossível pensar nas margens sem pensar no que elas encerram. A exemplo do texto de Michel Leiris que ocupa as margens da página do livro de Derrida (1972), conferindo-lhes visibili- 
dade e reduzindo a centralidade da página, são surpreendentes as estratégias encontradas por Diaz para colocar em evidência as margens da imagem, em seus múltiplos sentidos - culturais, artísticos, paisagísticos, naturais. Pelo agenciamento rizômico de seus personagens, a composição dos planos e a inserção de seus filmes em um hábito e uma cultura cinefílica, o cineasta afirma as potências estéticas dos limiares do cinema.

Se é provável que alguma nostalgia pelas experiências de imersão na sala escura em sua infância contribua para a duração estendida dos filmes de Diaz, mais proveitoso para nós é olhar seu gesto de maneira prospectiva, menos como nostalgia por algo que já não existe do que como afirmação de uma experiência que existe $\mathrm{e}$ resiste, sempre por ser re-definida, pronta para ter suas convenções abaladas. Ao final de uma sessão de Evolution of a Filipino Family ou de A Lullaby to the Sorrowful Mystery, pode ocorrer que os espectadores se olhem. Já se reconhecem, apesar da escuridão da sala, pois se viram nos intervalos, e é provável que sintam fazer parte de uma pequena comunidade, comunidade de testemunhas de uma história filipina pouco conhecida, de um cinema que tem aspectos de confidencial. A experiência comunitária da sala de cinema se fortalece.

\section{BIBLIOGRAFIA}

Adadol Ingawanij, May. 2015. "Long Walk to Life: The Films of Lav Diaz", Afterall 40, outono/inverno. https://www.afterall.org/journal/issue.40/long-walk-tolife the-films-of-lav-diaz. Acedido em 10 de janeiro de 2017.

Anderson, Benedict. 2005. Under Three Flags: Anarchism and the Anti-colonial Imagination. Londres: Verso.

-_-. 2008. Comunidades imaginadas. Reflexões sobre a origem e a difusão do nacionalismo. Trad. Denise Bottman. São Paulo: Companhia das Letras.

Aumont, Jacques. 2015. Montage. "La seule invention du cinéma". Paris: Vrin.

_-_. 2012. Que reste-t-il du cinéma? Paris: Vrin.

Balsom, Erika. 2007. "Saving the Image: Scale and Duration in Contemporary Art Cinema." Cineaction 72, 23-31.

Bazin, André. 2010 [1951]. "Pour un cinéma impur. Défense de l'adaptation". In Qu'est-ce que le cinéma, 81-106. Paris: Cerf.

Bhabha, Homi K. 1998. O local da cultura. Belo Horizonte: Editora UFMG. 
Bhabha, Homi K. 1994. The location of Culture. Londres e Nova Iorque: Routledge.

Bellour, Raymond. 1979. "Le texte introuvable". In L'analyse du film, 35-41. Paris: Albatros.

—_- 1997. Entre-imagens. Foto cinema vídeo. Trad. Luciana A. Penna Campinas: Papirus Editora.

- - - 2009. "Trente-cinq ans après, le 'texte' à nouveau entrouvable?”. In Images contemporaines, ed. por L. Vancheri, 17-33. Lyon: Aléas.

—_- 2011. "Le spectateur de cinéma: une mémoire unique". Trafic 79, outono.

Bonamy, Robert. 2013. Le Fond cinématographique. Paris: L'Harmattan.

Brown, William. 2016. "Melancholia: the long, slow cinema of Lav Diaz”. In Slow Cinema, ed. por Tiago de Luca e Nuno Barradas Jorge, 112-122. Edinburgo: Edinburgh University Press.

Crary, Jonathan. 2014. 24/7: Capitalismo tardio e os fins do sono. Trad. Joaquim Toledo Jr. São Paulo: Cosac Naify.

—_- 2012. Suspensões da percepção: Atenção, espetáculo e cultura moderna. São Paulo: Cosac Naify.

Dargis, Manohla e A. O Scott. 2011. "In Defense of the Slow and the Boring" New York Times, 3 de junho. http://www.nytimes.com/2011/06/05/movies/films-in-defense-of-slow-and-boring.html Acedido em 10 janeiro de 2017.

de Luca, Tiago, e Nuno Barradas Jorge (eds.). 2016. Slow Cinema. Edinburgo: Edinburgh University Press.

de Luca, Tiago. 2016. "Slow Cinema, Visible Cinema: Duration, Experience, and Spectatorship". Cinema Journal 56(1) outono: 23-42.

Derrida, Jacques. 1972. Marges de la philosophie. Paris: Minuit.

Diaz, Lav. 2016. "Philippines Year Zero" (Entrevista a Michael Guarnieri). Débordéments, 2 de outubro.

http://www.debordements.fr/spip.php?article534 Acedido em 10 de janeiro de 2017.

-——. 2014. "Entrevista com Lav Diaz" (Entrevista a Filipe Furtado). Cinética, 5 de maio.

http://revistacinetica.com.br/home/entrevista-com-lavdiaz/ Acedido em 10 de janeiro de 2017. 
Diaz, Lav. 2013. “Não acredito em público, faço cinema pelo cinema', diz diretor de filme de 11 horas" (entrevista a Ursula Passos). Folha de S. Paulo, 31 de outubro. http://www1.folha.uol.com.br/ilustrada/2013/10/1364820meu-cinema-nao-e-longo-e-livre-diz-lav-diaz-que-tem-obrade-12-horas.shtml. Acedido em 10 de janeiro de 2017.

Didi-Huberman, Georges. 2009. Survivance des lucioles. Paris: Minuit.

Flanagan, Matthew. 2008 "Towards an Aesthetic of Slow in Contemporary Cinema" in 16:9 6(29). http://www.16-9.dk/200811/side11_inenglish.htm. Acedido em 10 de janeiro de 2017).

Gaudreault, André e Philippe Marion. 2013. La fin du cinéma? Un média en crise à l'ère du numérique. Paris: Armand Colin.

Hobsbawn, Eric. 1990. Nações e nacionalismo desde 1780. Rio de Janeiro: Paz e Terra.

Hobsbawn, Eric, e Terence Ranger. 2012. A invenção das tradições. São Paulo: Paz e Terra.

James, Nick. 2010. “Passive-Aggressive”. Sight \& Sound 20(4): 5.

Jameson, Fredric. 1986. "Third World Literature in the Era of Multinational Capitalism”. Social Text 15, outono: 65-88.

Koepnick, Lutz. 2014. On Slowness: Toward an Aesthetic of the Contemporary. Nova Iorque: Columbia University Press.

Lodge, Guy. 2016. "Berlin Film Review: A Lullaby to the Sorrow Mystery". Variety, 18 de fevereiro.

http://variety.com/2016/film/reviews/a-lullaby-to-the-sorrowful-mystery-review-1201710010/

Mai, Nadin. 2015. The aesthetics of absence and duration in the posttrauma cinema of Lav Diaz. Tese de doutorado, Universidade de Stirling.

Monteiro, Lúcia Ramos. 2016. "Das narrativas de fundação às narrativas de dissolução: a questão da identidade nacional em filmes contemporâneos 'periféricos'”. Compós - XXV Encontro Anual da Compós. Universidade Federal de Goiás, Goiânia, junho de 2016, disponível em http://www.compos.org.br/biblioteca/ramos_monteiro_com pos 3357.pdf. Acedido em 10 de janeiro de 2017.

Mroz, Matilda. 2012. Temporality and Film Analysis. Edimburgo: Edinburgh University Press.

Münsterberg, Hugo. 1983 [1916]. “A atenção”. In A Experiência do cinema: antologia, org. por Ismail Xavier, 27-35. Rio de Janeiro: Edições Graal/Embrafilmes.

Mulvey, Laura. 2007. Death $24 x$ a Second. Stillness and the Moving Image. Londres: Reaktion Books. 
Nagib, Lúcia, e Anne Jerslev. 2013. Impure Cinema. Intermedial and Intercultural Approaches to Film. Londres: I.B. Tauris.

Romney, Jonathan. 2010. "In Search of Lost Time”. Sight and Sound 20(2): 43-44.

Shaviro, Steven. 2010. "Slow Cinema Vs Fast Films" The Pinocchio Theory, 12 de maio. http://www.shaviro.com/Blog/?p=891. Acedido em 10 de janeiro de 2017.

Shohat, Ella, e Robert Stam. 2006. Crítica da imagem eurocêntrica. São Paulo: Cosac Naify.

Sommer, Doris. 2004. Ficções de fundação. Os romances nacionais da América Latina. Belo Horizonte: Editora UFMG.

Truffaut, François. 1954. "Un trousseau de fausses clefs, Alfred Hitchcock". Cahiers du cinéma 39, outubro de 1954: 51.

\section{FILMOGRAFIA}

Florentina Hubaldo, CTE. [longa-metragem, PB, digital]. Dir. Lav Diaz. Sine Olivia Pilipinas. Filipinas, 2012. 360 mins.

A Lullaby to the Sorrowful Mystery (Hele sa hiwagang hapis). [longametragem, PB, digital]. Dir. Lav Diaz. Ten17 Productions/Epicmedia/Sine Olivia Pilipinas/Potocol/Akanga Film Productions. Filipinas/Singapura, 2016. 485 mins.

Submetido em 15-01-2017. Aceite para publicação em 15-05-2017. 